\author{
Professor Roland Iosif MORARU, PhD \\ E-mail: roland_moraru@yahoo.com \\ University of Petroșani \\ Assistant Professor Ana Petrina PĂUN, PhD Candidate \\ E-mail: stanciu.anapetrina@yahoo.com \\ University of Petroșani \\ Associate Professor Codruța Cornelia DURA, PhD \\ E-mail: codrutadura@gmail.com \\ University of Petroșani \\ Assistant Professor Ruxandra DINULESCU, PhD \\ E-mail: ruxandra.dinulescu@man.ase.ro \\ The Bucharest University of Economic Studies \\ Assistant Professor Ana-Madalina POTCOVARU, PhD \\ E-mail: ana.potcovaru@amp.ase.ro \\ The Bucharest University of Economic Studies
}

\title{
ANALYSIS OF THE DRIVERS OF OCCUPATIONAL HEALTH AND SAFETY PERFORMANCE DISCLOSURES BY ROMANIAN COMPANIES
}

Abstract. The paper addresses the issue of the disclosure of occupational health and safety (OHS) performances by the Romanian companies. Although under-researched in the literature, the topic received a great deal of attention after the Directive 2014/95/EU on non-financial reporting came into force. The study is aimed both at examining the extent to which OHS issues are disclosed within $C S R /$ sustainability reports and at establishing whether the quality of the disclosure is affected by a group of determinants such as: the size of the reporting company, its profitability, the ownership structure, the financial position and the company's age.

Keywords: Occupational Health and Safety, Corporate Social Responsibility, sustainability reporting, non-financial reporting, OHS global reporting index.

JEL Classification: M14, J28, I19, C40, C88

DOI: $10.24818 / 18423264 / 54.3 .20 .12$ 


\section{Introduction}

Given the current trends related to the globalization of business, the intensification of the competition is combined with the explosive development of information technology and determines the expiration of traditional organizational reporting practices focused exclusively on financial and accounting performance. An ever increasing number of corporations are adopting the regular practice of developing and publishing non-financial reports separately from their annual reports; therefore, addressing the issues related to the health and safety of the employees captured the fore attention of the specialists and practitioners in the field. The common thread of the empirical research focused on the phenomenon of Occupational Health and Safety (OHS) reporting lies in demonstrating high levels of reporting on Occupational Health and Safety issues, whether these reports are integrated into annual reports, sustainability reports or CSR reports, or that information they are made public on the corporate websites. Globally, the frequency of reporting OHS issues among corporations that issue non-financial reports was rated as very high, being in the range 70\% - 95\% (O’Neill, 2010).

However, in the literature, there are currently a small number of empirical studies conducted in Romania on CSR reporting and issues related to occupational safety and health (Deaconu et. al. 2018). But the few information we have found in the literature on this subject, only reinforce a belief that we have formed from the first moment we leaned on this topic, namely, the one related to the absence of a strategic approach on the communication of CSR and OHS issues among Romanian companies. In fact, as Gligor-Cimpoieru \& Munteanu (2014), points out, besides the subsidiaries of multinational corporations operating in our country, a very limited number of small and medium-sized enterprises in Romania have promoted the reporting of sustainability and / or CSR issues as a constant business practice (Gligor-Cimpoieru \& Munteanu, 2014).

\section{Research methodology}

Given the particular interest it presents, in the context of this research paper, not only the non-financial reporting of companies in Romania, but especially the reporting of the specific aspects of Occupational Health and Safety, we have made an effort to investigate the websites of the largest companies in Romania that incorporate OHS elements in their non-financial statements and reports and we have founded a complex database for a sample of 34 corporations Appendix 1 (Păun, 2019).

The dependent variable analyzed in the context of the empirical research conducted was called the global reporting index on OHS, and its foundation was set up on a quantitative-qualitative approach, based on the content analysis of the sustainability reports, respectively of the non-financial reports published by the companies selected in the analyzed sample. At the same time, the 
Analysis of the Drivers of Occupational Health and Safety Performance Disclosures by Romanian Companies

settlement of the global reporting index took into consideration the content of the customized standard GRI 403 - Occupational Health and Safety, version 2018 (Obrad \& Gherheș, 2018; Global Reporting Initiative, 2018).

Thus, in order to assign values as close to reality as possible to this composite index, we analyzed the useful information from the sustainability reports and systemized them according to the following areas of interest compatible with the GRI 403-2018 standard:

1. The managerial approach on OHS issues and the drawing of the nonfinancial report. There were considered aspects such as: the content of the OHS policy and its notoriety among the members of its own business organization members, respectively of the stakeholders; the functionality of the principles, rules and programs of organizational transformation in order to integrate OHS aspects; assimilation of OHS aspects among the key values that underpin the organizational culture; drawing up sustainability reports based on international reporting standards or own grids etc.;

2. Representation of employees in the OHS Committees, as an indispensable prerequisite for creating safe working systems by devising preventive measures to prevent work-related injuries and occupational diseases, with the participation of those directly involved;

3. OHS topics and programs addressed as a matter of priority. We analyzed aspects such as: the specific focus of the sample companies on designing and implementing their own programs, plans and indicators aimed at preventing and minimizing the risks of work injuries and occupational diseases; respectively the scheduling of audit activities and rigorous and systematic controls subordinated to the same major objectives related to OHS risks avoidance;

4. The disclosure of relevant statistical data on training sessions on safety and health at work, given that an increase in staff awareness across all levels of the organizational hierarchy on OHS issues is essential for increasing the efficiency of the activities carried out in this field;

5. Reporting of relevant indicators to reflect the efficiency of the OHS activity: injury rates, frequency of accidents with temporary incapacity for work, incidence of work injuries, number of recorded occupational disease cases, frequency of recorded dangerous incidents, absenteeism rate etc.

The maximum scores awarded for each of the 5 areas mentioned above, taking into account the importance of every last one in shaping OHS culture and improving reporting practices were the following: $\mathrm{I}_{1}$ - managerial approach in OHS domain (30); $\mathrm{I}_{2}$ - representation of employees in OHS committees (15); $\mathrm{I}_{3}$ - topics related to OHS (20); $\mathrm{I}_{4}-\mathrm{OHS}$ training (15); $\mathrm{I}_{5}$ - indicators of employee health status (20).

The correlated analysis of the 5 aspects of OHS for each of the 34 companies included in the research sample, allowed us to base the global OHS reporting indices, according to those presented in the last column of the database systematized in Appendix 1.

DOI: $10.24818 / 18423264 / 54.3 .20 .12$ 
In order to identify the independent variables that influence the reporting phenomenon in the field of OHS or sustainability, we have analyzed a significant number of empirical researches conducted in recent decades in different regions of the globe on this topic (Al-Hamadeen\& Badran, 2014; Behm \& Schneller, 2011; Habek \& Wolnibak, 2016; Hahn \& Kuhnen, 2013). In this research, we found a number of factors that were relevant in certain contexts, organizational cultures, characteristics of the business environment, time periods, etc. and we undertook a selection process in order to decant those drivers of reporting that proved to be the most appropriate in the context of our research, both in terms of their ability to explain the analyzed phenomenon and of the possibilities of obtaining statistical data necessary for their study (Dura et al., 2019).

The drivers presented in Appendix 2 have resulted, for which we subsequently identified the variables by which they can be characterized, the modalities by which these variables can be operationally customized within this research, as well as the way in which the working hypotheses to be verified in the research can be formulated.

\section{Normality analysis of distribution for the numerical variables}

The numerical variables subjected to the analysis, the indicators of the central tendency and the results of their normality test are summarized in table 1 . As we can see, some of the independent variables have a slightly asymmetric distribution. This phenomenon was expected to be encountered, because the sample was constituted taking into account only the reporting companies and the OHS aspects at the level of 2016-2017. Under these conditions, a number of economic indicators taken into account have inhomogeneous values: the turnover, the number of employees, the return on equity, the degree of indebtedness etc.

Table 1. Summary of preliminary descriptive analysis of numerical variables

\begin{tabular}{|l|c|c|c|c|c|c|c|c|c|}
\hline \multicolumn{1}{|c|}{ Variable } & $\begin{array}{c}\text { No. } \\
\text { of } \\
\text { cases }\end{array}$ & $\begin{array}{c}\text { Mini } \\
\text { mum } \\
\text { value }\end{array}$ & $\begin{array}{c}\text { Maxi } \\
\text { mum } \\
\text { value }\end{array}$ & Mean & $\begin{array}{c}\text { Me- } \\
\text { dian }\end{array}$ & \multicolumn{2}{c|}{$\begin{array}{c}\text { Mean } \\
\text { standard } \\
\text { deviation }\end{array}$} & \multicolumn{2}{|c|}{$\begin{array}{c}\text { Shapiro-Wilk } \\
\text { normality tests }\end{array}$} \\
\hline $\begin{array}{l}\text { OHS Global } \\
\text { Reporting } \\
\text { Index }\end{array}$ & 34 & 15 & 100 & 67.86 & 70 & 20.37 & 0.961 & 34 & 0.250 \\
\hline Turnover & 34 & 0.084 & 14.76 & 2.43 & 1.10 & 3.20 & 0.723 & 34 & 0.000 \\
\hline $\begin{array}{l}\text { Return on } \\
\text { equity (ROE) }\end{array}$ & 34 & - & 33.90 & 11.43 & 10.75 & 10.94 & 0.965 & 34 & 0.348 \\
\hline $\begin{array}{l}\text { The degree of } \\
\text { indebtedness }\end{array}$ & 34 & 9.65 & 93.64 & 39.86 & 30.81 & 25.50 & 0.878 & 34 & 0.001 \\
\hline $\begin{array}{l}\text { Corporation's } \\
\text { age }\end{array}$ & 34 & 2 & 28 & 20.28 & 22 & 7.56 & 0.887 & 34 & 0.002 \\
\hline
\end{tabular}


Analysis of the Drivers of Occupational Health and Safety Performance Disclosures by Romanian Companies

We will analyze the asymmetries identified on the basis of the descriptive primary analysis and introduce some restrictions to ensure the normality of some numerical variables, so that they are suitable afterwards for the correlation analysis.

For example, for the Turnover for the year 2017, we will highlight 3 layers of corporations:

- $\quad$ Corporations with a turnover of less than 1 billion lei: Zentiva, Vrancart, National Salt Society, S.I.E.P.C.O.F.A.R., Romstal, Rombat Metair, Patria Bank, KPMG, KMG Rompetrol Group, HeidelbergCement Romania, GSK Romania, Ciech Soda Romania, CEZ Romania, Antibiotics Iași, Antalis Romania, Aeorstar Bacău;

- $\quad$ Corporations with turnover comprised in the range [1-10] billion lei: Coca Cola HBC Romania, Raiffeisen Bank, Telekom, Lidl Romania, Ursus Breweries, Ameropa Romania, Transelectica, ADREM Invest, Heineken România, Romgaz, ArcelorMittal Galați, ALRO Slatina, Holcim, Auchan, Holzindustrie Schweighofer, Vodafone;

- Corporations with turnover of over 10 billion lei: Kaufland România and Petrom OMV.

For the first subsample we analyze the indicators of the central tendency, to which is added the evaluation of the indices of "curvature" or "sharpness" of the graphical representation (Skewness and Kurtosis). The result generated by the SPSS program is systematized in table 2 .

Table 2. Skewness and Kurtosis for sub-sample 1

\begin{tabular}{|l|l|r|}
\hline \multirow{2}{*}{ N } & Valid & 16 \\
\cline { 2 - 3 } & Missing & 0 \\
\hline Mean & $378,053,414.50$ \\
\hline Mode & $338,900,889.00$ \\
\hline Std. Deviation & $84,896,838^{\mathrm{a}}$ \\
\hline Skewness & $246,828,252.291$ \\
\hline Std. Error of Skewness & 1.058 \\
\hline Kurtosis & .564 \\
\hline Std. Error of Kurtosis & .542 \\
\hline a. Multiple modes exist. The smallest value is shown \\
\hline
\end{tabular}

We will analyze the normality based on the standard Skewness error (asymmetry) and the standard error of kurtosis (Std. Error of Kurtosis). The symmetry is fulfilled in a proportion of $99 \%$, when the coefficient of asymmetry (Skewness) is in the range: [- Standard error of Skewness; + Standard Skewness Error]. Also, the symmetry is $95 \%$ verified if Skewness is within a range of \pm 2 Std Error of Skewness.

Of course, the previous rule is also valid in the case of vaulting, measured by means of the vault coefficient (Kurtosis), for which it will be determined Std.

DOI: $10.24818 / 18423264 / 54.3 .20 .12$ 
Error of Kurtosis. In the case of the turnover for 2017 for the first sub-sample, Skewness $=1,058$, and $\pm 2 \cdot$ Std Error of Skewness $= \pm 2 \cdot 0.564= \pm 1,128$, Skewness being included in the respective range. Also, the Kurtosis vaulting coefficient $=0.542$, and the range $\pm 2 \cdot$ Std Error of kurtosis $= \pm 2 \cdot 1.091= \pm 2.182$, will include Kurtosis. Therefore, the symmetry of this variable is $95 \%$ verified.

For the second sub-sample, the indicators of central tendency, respectively of Skewness and Kurtosis asymmetry are presented in table 3. Therefore, there is only a $1 \%$ probability that this distribution will not be symmetrical and mesocortical. We will also apply the Kolmogorov Smirnov and Shapiro-Wilk normality tests. The results obtained are shown in table 4.

Table 3. Skewness and Kurtosis for sub-sample 2

\begin{tabular}{|l|lr|}
\hline \multirow{2}{*}{ N } & Valid & 16 \\
\cline { 2 - 3 } & Missing & 0 \\
\hline Mean & $3,249,265,080.06$ \\
\hline Mode & $2,658,910,473.00$ \\
\hline Std. Deviation & $1,051,272,937^{\mathrm{a}}$ \\
\hline Skewness & $1,801,759,923.605$ \\
\hline Std. Error of Skewness & .567 \\
\hline Kurtosis & .564 \\
\hline Std. Error of Kurtosis & -.972 \\
\hline a. Multiple modes exist. The smallest value is shown \\
\hline
\end{tabular}

Table 4. Testing the normality of the turnover for the companies in the sub-sample 2

\begin{tabular}{|l|c|c|c|c|c|c|}
\cline { 2 - 7 } \multicolumn{1}{c|}{} & \multicolumn{3}{c|}{ Kolmogorov-Smirnov ${ }^{\mathrm{a}}$} & \multicolumn{3}{c|}{ Shapiro-Wilk } \\
\cline { 2 - 7 } \multicolumn{1}{c|}{} & Statistic & df & Sig. & Statistic & df & Sig. \\
\hline Turnover (lei) 2017 & .179 & 16 & .180 & .908 & 16 & .109 \\
\hline
\end{tabular}

As $p>0.05$, the normality of the distribution of turnover values for 2017 at the level of this sub-sample is demonstrated. Following similar analyzes of the symmetry distribution achieved for the other numerical variables for 2017, we reached the following conclusions:

- The degree of indebtedness 2017 is an asymmetrical variable on the right, characterized by the concentration of most firms in the area of the degree of debt lower than the average. We will impose the condition the degree of indebtedness $<40 \%$. Under these conditions, we will keep only 21 corporations in the sample (those that fulfill the mentioned condition) and we will verify the normality of the resulting distribution. We can conclude that normality is assured because:

- the symmetry condition can be accepted with the $99 \%$ threshold (Skewness $=-0.234$ is between $+/$ - Std error of skewness $=0.501$ );

- the vaulting condition for Kurtosis is also 95\% verified (Kurtosis = 1.061 is between $+/-2 \cdot$ Standard error of Kurtosis $=+/ 0.972$ ). 
Analysis of the Drivers of Occupational Health and Safety Performance Disclosures by Romanian Companies

- Corporation's age - we performed the symmetry analysis according to the values of the Skewness and Kurtosis coefficients and we obtained the following results:

- the symmetry condition can be accepted with the 95\% threshold (Skewness $=-0.770$ is between $+/-2$ Std error of skewness $=+/-$ $0.806)$;

- the symmetry condition for Kurtosis is $99 \%$ verified (Kurtosis = 0.132 is between $+/$ - a standard error of Kurtosis $=+/ 1.576$ ).

Because the variable "age of the firm" is uni-modal, symmetrical and meso-kurtic, it turns out that its distribution is very close to normal.

4. Analysis of the dependence relations between the statistical variables

We will use the Pearson correlation coefficient to study the link between the global reporting index and the other numerical independent variables considered. Regarding the degree of capital concentration (quantified by means of a nominal variable), we will apply the analysis of variance (ANOVA) to highlight the eventual association with the quality of OHS reporting.

A. Analysis of the correlation between the global OHS reporting index and the turnover. Table 5 presents the results generated by the SPSS software for analyzing the correlation between the consistency of OHS reporting and the turnover of corporations in the first sub-sample.

Table 5. Correlation between OHS reporting index and turnover of corporations (sub-

\begin{tabular}{|l|l|c|c|}
\multicolumn{2}{c|}{ sample 1) } \\
\cline { 3 - 4 } \multicolumn{2}{|c|}{} & Turnover 2017 & $\begin{array}{c}\text { OHS global } \\
\text { reporting index }\end{array}$ \\
\hline \multirow{3}{*}{ Turnover 2017} & Pearson Correlation & 1 & -.071 \\
\cline { 2 - 4 } & Sig. (2-tailed) & & .795 \\
\cline { 2 - 4 } & $\mathrm{N}$ & 16 & 16 \\
\hline \multirow{3}{*}{ OHS global reporting index } & Pearson Correlation & -.071 & 1 \\
\cline { 2 - 4 } & Sig. (2-tailed) & .795 & 16 \\
\cline { 2 - 4 } & $\mathrm{N}$ & 16 & \\
\hline
\end{tabular}

The table allows reading the Pearson correlation $\mathrm{r}(14)=-0.071$, when $\mathrm{p}=$ $0.795>0.05$, and 14 represents the number of degrees of freedom equal to $(N-2)$. Therefore, the null hypothesis is accepted and the conclusion that between the turnover of the companies in the first sub-sample and the global OHS reporting index there is no statistically significant correlation, is maintained. Based on the data provided by the SPSS software, we analyze further on the existence of a link between the turnover of the companies in the second sub-sample and the OHS reporting index. In this case we obtain, $\mathrm{r}(14)=0.226$ and $\mathrm{p}=0.400>0.05$. Again we accept the null hypothesis and admit that there is no significant correlation between the turnover of the analyzed companies and the global SSM reporting index.

DOI: $10.24818 / 18423264 / 54.3 .20 .12$ 
Regarding the third sub-sample, it consisted of only two companies that recorded extreme and / or aberrant values regarding the turnover indicator: Petrom OMV with a sales volume of 14,764,836,448 lei and Kaufland Romania with a sales volume of 10,086,636,311 lei. Obviously, it does not make sense to determine the Pearson correlation coefficient for these two companies, but we can notice the high values of the global OSH index: 100 for Petrom OMV and 70 for Kaufland, which leads us to believe that these companies are among the performers of sustainability reporting (implicitly of OHS reporting) in Romania.

However, we find that OHS reporting is not in close interdependence with the turnover of the sample corporations. This result is convergent with other empirical studies in the literature. For example, Chow and Wong-Boren conducted a research in which they separately addressed voluntary reporting and mandatory reporting, concluding that only voluntary CSR reporting could be associated with company characteristics and in particular with their size, size which can be assessed by the turnover, number of employees or total assets (Chow $\&$ Wong-Boren, 1987). This premise is verified in the case of the sample of the 34 Romanian corporations analyzed, if we consider that their reporting in accordance with the Directive 2014/95 / EU tends to become compulsory rather than voluntary.

B. Analysis of the correlation between the OHS global reporting index and the degree of indebtedness.

The calculations underlying the determination of the Pearson correlation coefficient, performed using SPSS software are shown in table 6. Since r (19) = 0.544 and $p=0.011<0.05$, the null hypothesis will be rejected and we can consider this correlation as significant.

Table 6. Pearson correlation between OHS global reporting index and variable total indebtedness level

\begin{tabular}{|l|l|c|c|}
\cline { 3 - 4 } \multicolumn{2}{c|}{} & $\begin{array}{c}\text { OHS global } \\
\text { reporting index }\end{array}$ & $\begin{array}{c}\text { The indebtedness } \\
\text { level } \\
(\%)\end{array}$ \\
\hline \multirow{2}{*}{$\begin{array}{l}\text { OHS global reporting } \\
\text { index }\end{array}$} & Pearson Correlation & 1 & $-.544^{*}$ \\
\cline { 2 - 4 } & Sig. (2-tailed) & & .011 \\
\cline { 2 - 4 } $\begin{array}{l}\text { The indebtedness level } \\
(\%)\end{array}$ & Pearson Correlation & $-.544^{*}$ & 21 \\
\cline { 2 - 4 } & Sig. (2-tailed) & .011 & 1 \\
\cline { 2 - 4 } & $\mathrm{N}$ & 21 & 21 \\
\hline \multirow{2}{*}{ *. Correlation is significant at the 0.05 level (2-tailed). } \\
\hline
\end{tabular}

According to the Hopkins grid, the correlation can be considered as major, and the coefficient of determination $r^{2}=0,2959$. In other words, $29.59 \%$ of the variation in the global OHS reporting index can be accounted for the spread of corporate indebtedness. In this case, the confidence limits for the correlation coefficient between the OHS global reporting index and the total indebtedness level are: $r_{\text {inf }}=0.146$ and $r_{\text {sup }}=0.790$. 
Analysis of the Drivers of Occupational Health and Safety Performance Disclosures by Romanian Companies

The identified correlation is negative; in other words, corporations with a low degree of debt and a relatively large number of investors are more open to developing and communicating CSR / sustainability reports, within which the OHS component is well represented.

C. Analysis of the correlation between the OHS global reporting index and the return on equity (ROE).

In this case, we started from the construction of the graph through points illustrated in figure 1 and we analyzed, as a first step, the possible dependence between the two variables.

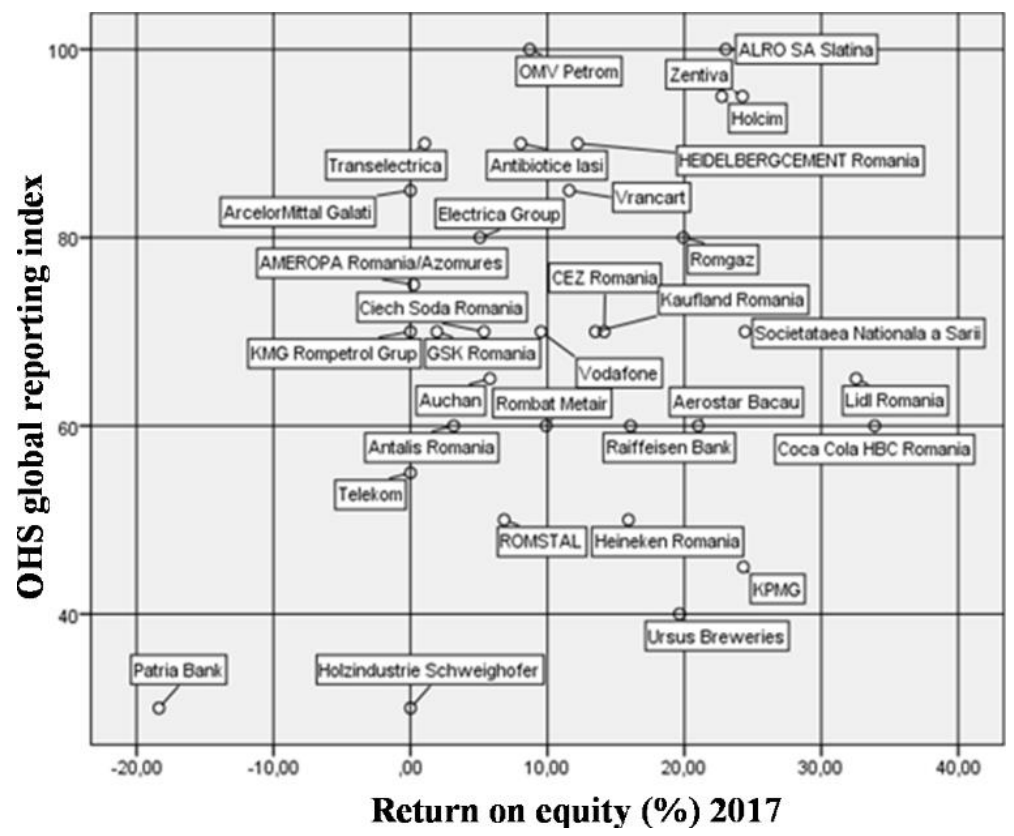

Figure 1: Graphical representation of the global OHS reporting index and of the return of equity for the companies in the sample under investigation

The chart shows two companies with global OHS reporting index below value 40 and low values of the return on equity: these are Patria Bank and Holzindustrie Schweighofer. For the OHS global reporting index between 40 and 60 , we can observe 10 cases of companies with an average return on equity of $m=$ 15.077 and a standard deviation of $s=10.33477$. These descriptive statistics indicators indicate a wide spread of the values of the two variables at the level of this sub-sample. The third sub-sample delimited on the basis of the representation in figure 1, includes 10 other companies with the global reporting index included in the open range (60-80). For this sub-sample, we have an average return on equity of $m=10.749$, with a standard deviation of $s=10.74874$. Finally, for the last level

DOI: $10.24818 / 18423264 / 54.3 .20 .12$ 
with the global OHS reporting index comprised between [80-100], we identified 11 companies with the mean ROE $m=12.4173$ and the standard deviation $s=8.86684$.

Taking into account the allure of the graph in figure 1 and the values of the descriptive statistics indicators highlighted above, we predict a weak or insignificant correlation between the two variables. The results provided by the SPSS software for analyzing this correlation are summarized in Table 7.

Table 7. Pearson correlation between OHS global reporting index and return on

\begin{tabular}{|l|l|c|c|}
\multicolumn{2}{c|}{ equity (ROE) } \\
\cline { 3 - 4 } \multicolumn{2}{|c|}{} & $\begin{array}{c}\text { Return on } \\
\text { equity }(\%)\end{array}$ & $\begin{array}{c}\text { OHS global } \\
\text { reporting } \\
\text { index }\end{array}$ \\
\hline \multirow{3}{*}{ Return of equity $(\%)$} & Pearson Correlation & 1 & .197 \\
\cline { 2 - 4 } & Sig. (2-tailed) & & .271 \\
\cline { 2 - 4 } & $\mathrm{N}$ & 34 & 33 \\
\hline \multirow{3}{*}{ OHS global reporting index } & Pearson Correlation & .197 & 1 \\
\cline { 2 - 4 } & Sig. (2-tailed) & .271 & 34 \\
\cline { 2 - 4 } & $\mathrm{N}$ & 33 & \\
\hline
\end{tabular}

We obtain $\mathrm{r}(31)=0.197$ and $\mathrm{p}=0.271>0.05$, which leads us to the conclusion that the null hypothesis will be accepted. Therefore, there is no significant association between the OHS global reporting index and the profitability of companies, estimated based on the return on equity (ROE) at the sample level of the 34 reporting companies in Romania, in 2017.

In the literature, the analysis of the correlation between sustainability reporting and corporate financial results is a widely debated issue, which has led, over time, to ambiguous empirical results. Thus, while a significant number of researchers report a positive link between the two variables, there are several other relevant examples that support the opposite hypothesis: the relationship is negative or neutral (Dumitrescu\&Simionescu, 2015; Dura et al, 2018; Tiron-Tudor et al., 2019; Vuță et. al., 2019). In the latter situation, cases were frequently exemplified in which the managers of the reporting corporations exaggeratedly emphasized the positive aspects of sustainability, and this "myopia" led to the partial compromise of the interests and objectives of relevant stakeholders (Galant \& Cadez, 2017).

D. Analysis of the correlation between the OHS global reporting index and the age of the corporation. In this case, we determined the Pearson correlation coefficient for a number of 33 companies, and the results presented in the table no. 8 , shows a statistically significant correlation. Thus, $\mathrm{r}(31)=0.432$ and $\mathrm{p}=0.012<0.05$ show that there is an association of average intensity between the two variables.

We calculate the coefficient of determination $d=0.1866$, and based on this result we conclude that the spread of the global SSM reporting index is due in proportion of $18.66 \%$ to the variable "age of the corporation". Using the table for 
Analysis of the Drivers of Occupational Health and Safety Performance Disclosures by Romanian Companies

transforming $\mathrm{r}$ values into $\mathrm{Z}$ scores, we conclude that the confidence limits for the correlation coefficient between the global SSM reporting index and the age of the firm are between $r_{\text {inf }}=0.0196$ and $r_{\text {sup }}=0.6819$.

Table 8. The Pearson correlation between the OHS global reporting index and the age of the corporations in the sample

\begin{tabular}{|l|l|c|c|}
\cline { 3 - 4 } \multicolumn{2}{c|}{} & $\begin{array}{c}\text { OHS global } \\
\text { reporting index }\end{array}$ & $\begin{array}{c}\text { Corporation's } \\
\text { age (years) }\end{array}$ \\
\hline \multirow{2}{*}{$\begin{array}{l}\text { OHS global reporting } \\
\text { index }\end{array}$} & Pearson Correlation & 1 & $.432^{*}$ \\
\cline { 2 - 4 } & Sig. (2-tailed) & & .012 \\
\cline { 2 - 4 } $\begin{array}{l}\text { Corporation's age } \\
\text { (years) }\end{array}$ & Pearson Correlation & 34 & 33 \\
\cline { 2 - 4 } & Sig. (2-tailed) & $.432^{*}$ & 1 \\
\cline { 2 - 4 } & $\mathrm{N}$ & 33 & 34 \\
\hline \multirow{2}{*}{ *. Correlation is significant at the 0.05 level (2-tailed). } \\
\hline
\end{tabular}

More than one year after the transposition of Directive 2014/95 / EU into the Romanian legislation, still at the national level there is an extremely small number of corporations that have made the necessary efforts to comply with the new legislative restrictions; this proves that the preparation of the business environment in our country for the compliance with the rigors derived from the non-financial reporting will be a long-term exercise, given that the experience of the reporting companies is one of the essential ingredients that determine the great performers in the field of sustainability to continue their efforts in this direction, despite the inherent costs and difficulties: the large number of working hours involved in the preparation of such a report, the absence of an internal budget dedicated to reporting, the absence of specific internal procedures, the reluctance of some managers and employees regarding the disclosure of non-financial information etc. (Raiffeisen Bank et al., 2017).

E. Analysis of the dependence between the OHS Global Reporting Index and the concentration of the reporting corporation's capital. Because the degree of capital concentration is a nominally measured variable that has three distinct categories according to Appendix 2, we will use the ANOVA method to investigate a possible association between this and the dependent variable.

For this purpose, we will first check the condition of normality of the dependent variable on each category of the independent variable. The output generated by the SPSS program is shown in table 9. The dependent variable - the OHS global reporting index - is normally distributed across all categories of the independent variable because the Shapiro-Wilk test results indicate that Sig. (p)> 0.05 , which causes us to accept the null hypothesis for each situation.

Next, we test the homogeneity of the dispersions using the Levene test, which leads us to the results presented in table 10.

The Levene test is a statistical Fisher test, for which the calculated value

DOI: $10.24818 / 18423264 / 54.3 .20 .12$ 
(called "statistical Levene") is compared with a critical value extracted from the table of the Fisher's distribution law, chosen according to the probability of guaranteeing the desired result and the degrees of freedom highlighted in the table above $\left(\mathrm{df}_{1}\right.$ and $\left.\mathrm{df}_{2}\right)$. Because $\mathrm{F}_{\text {calc.0.05;2;32 }}=0.667<\mathrm{F}_{\text {tab.0.05;2;32 }}=3.316$, it follows that Sig. $(p)=0.520>0.05$. Therefore, the test confirms that the homogeneity of the dispersions is ensured.

Table 9. Checking the normality of the variable "degree of capital concentration"

\begin{tabular}{|c|c|c|c|c|c|c|c|}
\hline & & & & & & & \\
\hline & \multirow[t]{2}{*}{$\begin{array}{l}\text { Degree of capital } \\
\text { concentration }\end{array}$} & \multicolumn{3}{|c|}{$\begin{array}{l}\text { Kolmogorov- } \\
\text { Smirnov }^{\mathrm{a}}\end{array}$} & \multicolumn{3}{|c|}{ Shapiro-Wilk } \\
\hline & & Statistic & df & Sig. & Statistic & $\mathrm{df}$ & Sig. \\
\hline \multirow{3}{*}{$\begin{array}{l}\text { OHS global reporting } \\
\text { index }\end{array}$} & Concentrated & .129 & 20 & $.200^{*}$ & .961 & 20 & .573 \\
\hline & $\begin{array}{l}\text { Medium } \\
\text { fragmentation }\end{array}$ & 184 & 8 & $.200^{*}$ & .926 & 8 & .477 \\
\hline & High fragmentation & .170 & 7 & $200^{*}$ & .980 & 7 & .958 \\
\hline
\end{tabular}

*. This is a lower bound of the true significance.

a. Lilliefors Significance Correction

Table 10. Dispersion homogeneity testing - Global OHS reporting index

\begin{tabular}{|c|c|c|c|}
\hline Levene Statistic & $\mathrm{df}_{1}$ & $\mathrm{df}_{2}$ & Sig. \\
\hline .667 & 2 & 32 & .520 \\
\hline
\end{tabular}

Testing the differences that actually exist between the means of the analyzed variables represents the step that needs to be taken further and which is able to reflect whether the independent variable actually has a significant impact on the dependent variable.

For this purpose, the SPSS program will generate the ANOVA variance analysis table which will present the total variance decomposed on the two sources: the effect exerted by the independent variable (the variance between groups) and the effect due to other factors (the variance within the groups). The same table will also indicate the calculated value of $F$ used in order to test the differences recorded between the groups means to perform the test; the result of the effective application of the Fisher statistical test is given by the value "Sig." of the last column, depending on which we will decide whether we accept or reject the null hypothesis.

In order to find out how the degree of capital concentration influences the OHS global reporting index, we employ the ANOVA method and the table generated by the SPSS program is shown in table 11:

Table 11. Analysis of variances (ANOVA) - OHS Global reporting index

\begin{tabular}{|l|r|c|c|c|c|}
\cline { 2 - 6 } \multicolumn{1}{c|}{} & Sum of Squares & df & Mean Square & F & Sig. \\
\hline Between Groups & 890.982 & 2 & 445.491 & 1.078 & .352 \\
\hline Within Groups & 13223.304 & 32 & 413.228 & & \\
\hline Total & 14114.286 & 34 & & & \\
\hline
\end{tabular}


Analysis of the Drivers of Occupational Health and Safety Performance Disclosures by Romanian Companies

The ANOVA test leads us to a value $\mathrm{F}(2.32)=1.078$, respectively $\mathrm{p}=$ $0.352>0.05$. Therefore, from a statistical point of view, we cannot reject the null hypothesis, resulting that there are no significant differences between the averages of the OHS global reporting index regarding the three categories of companies defined by various degrees of capital concentration.

\section{Conclusions}

The results of the investigations carried out on the variables that influence the phenomenon of reporting the corporate performances achieved in the field of occupational safety and health can be summarized as follows: from the total of the five variables analyzed, the financial soundness expressed by the degree of indebtedness of the corporation, respectively its age, which represents an important indicator of the experience accumulated in the reporting, were detached as variables with a significant impact on the quality of reporting on OHS issues. Regarding the variable „degree of capital concentration”, a more detailed analysis performed with the help of graphical tools provided by SPSS, allowed us to conclude that companies with a high capital fragmentation in which the majority shareholder owns less than $55 \%$ of capital has a higher average of the reporting index compared to the other two categories $(74.286$, compared with 69, respectively 59.375). The most plausible explanation would be that a fragmented shareholding exerts greater pressure on the management of the company in terms of transparency, consistency and quality of sustainability reporting.

Despite the novelty of the research, the authors are aware of some limitations inherent to it. Thus, the volume of the analyzed sample included 34 corporations, an overwhelming part of them counting in the category of large companies in Romania. Although the selection of these corporations in the sample was strongly impacted by the limited size of the total population formed by the reporting companies of the OHS aspects in Romania, we cannot omit the fact that the study undertaken offers little information regarding the analysis of this phenomenon among small and medium businesses in Romania (Dura et al., 2017).

From this perspective, we believe that our research could be expanded in the future by two major directions. Firstly, in the coming years it will certainly be possible to establish a larger sample made up of corporations that have adopted the practice of sustainability reporting and have accumulated some expertise in this area.

Secondly, a quantitative study such as the present one, can be accompanied by a qualitative research that would include interviews with top managers and / or OHS / sustainability managers within the Romanian corporations, with the purpose of x-raying "from inside" the phenomenon of reporting with its pluses and minuses, with the indisputable image advantages it brings to corporations, but also with the

DOI: $10.24818 / 18423264 / 54.3 .20 .12$ 
Roland Moraru, Ana Păun, Codruța Dura, Ruxandra Dinulescu, Ana Potcovaru

costs and difficulties involved in the process of collecting and periodically synthesizing a large volume of data from various fields.

\section{REFERENCES}

[1] Al-Hamadeen, R., Badran, S. (2014), Nature and Determinants of CSR Disclosure: Experience of the Jordanian Public Shareholding Companies, European Journal of Business and Management, 6 (13): 18-34;

[2] Behm, M., Schneller, A. (2011), Externally Reported Occupational Health \& Safety Data Among U.S. Manufacturing Firms, Journal of Safety, Health \& Environmental Research, 7(1): 10-15;

[3] Chow, C., Wong-Boren, A. (1987), Voluntary Financial Disclosure by Mexican Corporations, The Accounting Review, 62(2): 533-541;

[4] Deaconu, A., Gogu, E., Radu, C., Tudor, M. (2018), Sustainable Economic Development, Economic Equilibrium and Work Productivity on Industries of the Romanian National Economy, 2000-2015; Economic Computation and Economic Cybernetics Studies and Research; ASE Publishing; 52 (1): 25-42;

[5] Dumitrescu, D., Simionescu, L. (2015), Empirical Research Regarding the Influence of Corporate Social Responsibility (CSR) Activities on Company's Employees and Financial Performance; Economic Computation and Economic Cybernetics Studies and Research; ASE Publishing; 49 (3), 52-66;

[6] Dura, C., Drigă, I., Păun A. P. (2019), OHS Disclosure in Romania in the Framework of CSR Reporting; Supplement of Quality - Access to Success Journal, 20: 429-435;

[7] Dura, C., Păun A. P., Moraru R. (2018), Empirical Analysis on the Relationship between Corporate Health and Safety Performance and the Financial Outcome within Socially Responsible Companies; Quality - Access to Success Journal, 19 (162): 155-160;

[8] Dura, C., Drigă, I., Isac, C. (2017), Environmental Reporting by Oil and Gas Multinationals from Russia and Romania: A Comparative Analysis,

Environmental Engineering and Management Journal, 16 (6): 1269-1274;

[9] Galant, A., Cadez, S. (2017), Corporate Social Responsibility and Financial Performance Relationship: A Review of Measurement Approaches, Economic Research, 30 (1): 676-693;

[10] Gligor-Cimpoieru, D., C., Munteanu, V., P. (2014), External CSR

Communication in a Strategic Approach; Economia. Seria Management, Vol. 17, No. 2, 2014, pp.276-289;

[11] Habek, P., Wolnibak, R. (2016), Assessing the Quality of Corporate Social Responsibility Reports: The Case of Reporting Practices in Selected European Union Member States; Quality\&Quantity, 50 (1): 399-420;

[12] Hahn, R., Kuhnen, M.(2013), Determinants of Sustainability Reporting: A Review of Results, Trends, Theory, and Opportunities in an Expanding Field of Research; Journal of Cleaner Production 59: 5-21; 
Analysis of the Drivers of Occupational Health and Safety Performance Disclosures by Romanian Companies

[13] Obrad, C., Gherheș, V. (2018), A Human Resource Perspective on Responsible Corporate Behavior. Case Study: The Multinational Companies in Western Romania; Sustainability, 10 (726);

[14] O'Neill (2010), Accounting for Lost Time: Examining Corporate Accountability to Stakeholders for Occupational Health and Safety; $\mathrm{PhD}$ Thesis, RMIT University;

[15] Păun, A., P. (2019), Research on Occupational Health and Safety Performance within the Framework of Corporate Social Responsbility; $\mathrm{PhD}$ Thesis, University of Petroșani;

[16] Tiron-Tudor, A., Nistor, C.,S., Ștefănescu, C.,A., Zanellato, G. (2019), Encompassing Non-Financial Reporting in A Coercive Framework for Enhancing Social Responsibility: Romanian Listed Companies' Case; Amfiteatru Economic, 21(52): 590-606;

[17] Vuță, M., Cioacă, S., I., Vuță, M., Enciu, A. (2019), An Empirical Analysis of Corporate Social Responsibility Effects on Financial Performance for Romanian Listed Companies; Amfiteatru Economic, 21 (52): 607-622; [18] Raiffeisen Bank, The Romanian Centre for European Policies and Romanian Business Leaders (2017), Non-financial reporting seen by performers [19] Global Reporting Initiative (2018), GRI 403 Standard: Occupational Health \& Safety;

[20] www.risco.ro, RisCo Business Intelligence.

DOI: $10.24818 / 18423264 / 54.3 .20 .12$ 
Economic Computation and Economic Cybernetics Studies and Research, Issue 3/2020

\begin{tabular}{|c|c|c|c|c|c|c|c|}
\hline \multicolumn{8}{|c|}{ Appendix 1. Database comprising 34 Romanian companies included in the sample and the analyzed variables [RisCo] } \\
\hline $\begin{array}{l}\text { Crt. } \\
\text { No. }\end{array}$ & Company name & $\begin{array}{c}\text { Turnover } \\
2017\end{array}$ & $\begin{array}{c}\text { Return on } \\
\text { equity } \\
2017\end{array}$ & $\begin{array}{c}\text { Total } \\
\text { indebtedness } \\
\text { level } 2017\end{array}$ & $\begin{array}{c}\text { Corporation's } \\
\text { age }\end{array}$ & $\begin{array}{l}\text { Degree of capital } \\
\text { concentration }\end{array}$ & $\begin{array}{c}\text { OHS Global } \\
\text { Reporting Index }\end{array}$ \\
\hline 1 & Antibiotics Iaşi & $337,629,448$ & 8.05 & 25.94 & 28 & High fragmentation & 90 \\
\hline 2 & $\begin{array}{l}\text { Coca Cola HBC } \\
\text { România }\end{array}$ & $2,218,998,534$ & 33.9 & 25.59 & 27 & High fragmentation & 60 \\
\hline 3 & Heineken România & $1,160,229,860$ & 15.92 & 28.28 & 17 & Concentrated & 50 \\
\hline 4 & Ursus Breweries & $1,705,841,267$ & 19.64 & 33.66 & 14 & Concentrated & 40 \\
\hline 5 & Zentiva & $458,377,044$ & 24.24 & 20.23 & 28 & Concentrated & 95 \\
\hline 6 & Auchan & $5,223,286,301$ & 5.8 & 56.56 & 14 & Concentrated & 65 \\
\hline 7 & GSK România & $423,560,799$ & 1.93 & 12.42 & 18 & Concentrated & 70 \\
\hline 8 & Kaufland România & $10,086,636,311$ & 13.5 & 32.57 & 16 & Concentrated & 70 \\
\hline 9 & Lidl România & $6,510,008,485$ & 32.54 & 62.25 & 12 & Concentrated & 65 \\
\hline 10 & ROMSTAL & $659,217,381$ & 6.84 & 32.19 & 25 & High fragmentation & 50 \\
\hline 11 & SIEPCOFAR & $880,528,121$ & 12.15 & 76.49 & 27 & Medium fragmentation & 15 \\
\hline 12 & ADREM Invest & $115,799,922$ & 10.89 & 92.96 & 13 & Concentrated & 75 \\
\hline 13 & Antalis România & $84,896,838$ & 3.16 & 26.31 & 21 & Medium fragmentation & 60 \\
\hline 14 & KPMG & $95,777,079$ & 24.31 & 38.33 & 24 & Concentrated & 45 \\
\hline 15 & Patria Bank & $187,722,000$ & -18.37 & 93.64 & 3 & Medium fragmentation & 30 \\
\hline 16 & Raiffeisen Bank & $2,603,000,000$ & 16.07 & 90.23 & 28 & Concentrated & 60 \\
\hline 17 & Telekom & $2,714,820,946$ & 0 & 27.84 & 22 & Medium fragmentation & 55 \\
\hline 18 & Vodafone & $4,545,439,472$ & 9.53 & 58.26 & 23 & Concentrated & 70 \\
\hline 19 & KMG Rompetrol Grup & $190,171,762$ & 0 & 92.5 & 9 & High fragmentation & 70 \\
\hline 20 & OMV Petrom & $14,764,836,448$ & 8.71 & 11 & 22 & High fragmentation & 100 \\
\hline
\end{tabular}

\begin{tabular}{l|l|l}
20 & OMV Petrom & $14,764,836,448$ \\
\hline
\end{tabular}

DOI: 10.24818/18423264/54.3.20.12 
Analysis of the Drivers of Occupational Health and Safety Performance Disclosures by Romanian Companies

\begin{tabular}{|c|c|c|c|c|c|c|c|}
\hline 21 & Romgaz & $4,585,189,388$ & 19.92 & 11.54 & 18 & Medium fragmentation & 80 \\
\hline 22 & National Salt Society & $317,180,887$ & 24.43 & 13.08 & 9 & High fragmentation & 70 \\
\hline 23 & ALRO Slatina & $2,480,775,721$ & 23.03 & 44.51 & 28 & Concentrated & 100 \\
\hline 24 & $\begin{array}{l}\text { AMEROPA România } \\
\text { /Azomureș }\end{array}$ & $1,447,333,215$ & 0.24 & 46.26 & 28 & Concentrated & 75 \\
\hline 25 & ArcelorMittal Galaţi & $4,661,907,896$ & 0 & 63.67 & 28 & Concentrated & 85 \\
\hline 26 & Ciech Soda România & $389,511,192$ & 5.37 & 21.94 & 28 & Concentrated & 70 \\
\hline 27 & $\begin{array}{l}\text { Heidelberg Cement } \\
\text { România }\end{array}$ & $890,530,183$ & 12.21 & 12.72 & 21 & Concentrated & 90 \\
\hline 28 & Holcim & $1,051,272,937$ & 22.73 & 50.13 & 17 & Concentrated & 95 \\
\hline 29 & $\begin{array}{l}\text { Holzindustrie } \\
\text { Schweighofer }\end{array}$ & $1,769,381,279$ & 0 & 29.44 & 2 & Concentrated & 30 \\
\hline 30 & CEZ România & $147,570,316$ & 14.15 & 92.75 & 14 & Concentrated & 70 \\
\hline 31 & Transelectrica & $3,015,023,896$ & 1.04 & 27.63 & 19 & Medium fragmentation & 90 \\
\hline 32 & Aerostar Bacău & $340,172,330$ & 21.02 & 9.65 & 28 & Medium fragmentation & 60 \\
\hline 33 & Rombat Metair & $386,005,630$ & 9.91 & 20.89 & 28 & Concentrated & 60 \\
\hline 34 & Vrancart & $260,003,622$ & 11.59 & 40.74 & 28 & Medium fragmentation & 85 \\
\hline
\end{tabular}

DOI: $10.24818 / 18423264 / 54.3 .20 .12$ 
Roland Moraru, Ana Păun, Codruța Dura, Ruxandra Dinulescu, Ana Potcovaru

Appendix 2. The drivers of OHS reporting, the variables included in the research and the working hypotheses

\begin{tabular}{|c|c|c|c|c|}
\hline $\begin{array}{c}\text { Name of the } \\
\text { influence factor }\end{array}$ & $\begin{array}{c}\text { Corresponding } \\
\text { variable }\end{array}$ & Operational definition & Formulation of null hypotheses & $\begin{array}{c}\text { The type of } \\
\text { variable }\end{array}$ \\
\hline $\begin{array}{l}\text { The shareholder of the } \\
\text { company }\end{array}$ & $\begin{array}{l}\text { The degree of capital } \\
\text { concentration }\end{array}$ & $\begin{array}{l}\text { high capital fragmentation, if the majority shareholder owns } \\
\text { [0-54.99\%] of the capital; } \\
\text { medium capital fragmentation, if the majority shareholder } \\
\text { owns [55\%-84.99\%] of the capital; } \\
\text { - } \text { high degree of capital concentration, if the majority } \\
\text { shareholder owns over } 85 \% \text { of the capital }\end{array}$ & $\begin{array}{l}\mathrm{H}_{0 \mathrm{~A}}: \text { "The value of the global OHS } \\
\text { reporting index does not depend on the } \\
\text { degree of capital concentration" }\end{array}$ & Categorical \\
\hline $\begin{array}{l}\text { The size of the } \\
\text { corporation }\end{array}$ & Turnover & The total annual income of the corporation & $\begin{array}{l}\mathrm{H}_{0 \mathrm{~B}}: \text { " The value of the global OHS } \\
\text { reporting index does not depend on } \\
\text { turnover" }\end{array}$ & Numeric \\
\hline Profitability & Return on equity & $\mathrm{ROE}=($ Net result $) /(\mathrm{Own}$ capital $) \times 100$ & $\begin{array}{l}\mathrm{H}_{0 \mathrm{C}} \text { : " The value of the global OHS } \\
\text { reporting index does not depend on the } \\
\text { return on equity" }\end{array}$ & Numeric \\
\hline Financial soundness & $\begin{array}{l}\text { Total indebtedness } \\
\text { level }\end{array}$ & $\mathrm{GI}=($ Debts$/$ Total assets $) \times 100$ & $\begin{array}{l}\mathrm{H}_{0 \mathrm{D}} \text { : " The value of the global OHS } \\
\text { reporting index does not depend on the } \\
\text { degree of corporate indebtedness" }\end{array}$ & Numeric \\
\hline Reporting routine & Corporation's age & Number of years since its inception & $\begin{array}{c}\mathrm{H}_{0 \mathrm{E}}: \text { "The value of the global SSM reporting } \\
\text { index does not depend on the age of the } \\
\text { corporation" }\end{array}$ & Numeric \\
\hline
\end{tabular}

